\title{
THE EFFECT OF INSULIN COMA AND E.C.T. ON THE THREE-YEAR PROGNOSIS OF SCHIZOPHRENIA
}

\author{
BY \\ D. M. LEIBERMAN, J. HOENIG, and I. AUERBACH \\ From the Bethlem Royal and the Maudsley Hospital, London
}

The evaluation of the effects of the special physical methods of treatment of schizophrenia -insulin coma and electroconvulsive therapy-requires not only an assessment of the short-term results but also continued follow-up of the patients over a long period. Three factors in particular make assessment of the effects of any form of treatment in this disease difficult: first, the elusive character of the illness which defies exact definition and measurement in the individual patient; secondly, the variability of the interaction between the patient and his illness and the social environment; and thirdly, the tendency of schizophrenia to spontaneous remission. Several authors (David, 1954; Malamud and Render, 1939; Lewis, 1945) have pointed out the methodological shortcomings of many previous attempts to evaluate the results of the treatments in schizophrenia and have suggested reasons to account for the large discrepancies and even contradictions in the various findings. In a previous communication Hoenig, Leiberman, and Auerbach (1956) discussed this problem and attempted to overcome the difficulties by three measures. (1) Two groups of patients from the same hospital, admitted at different periods, that is before and after the introduction of physical methods of treatment, were compared. The admission policy of the hospital had remained unchanged throughout. (2) The cases selected for investigation were all the patients suffering from schizophrenia admitted in the periods under investigation, who had been ill for not longer than one year; the two groups were comparable in all relevant respects. One group had been admitted to the Maudsley Hospital in the years 1934-35, the other group had been admitted to the combined Bethlem Royal and Maudsley Hospitals in 1948-50. (3) The later group consisted of a treated and an untreated section; this allowed an internal check of the significance of any differences found between the two main groups.

In the previous report referred to above (loc. cit.) the results at the time of discharge after the first admission were assessed, and there was suggestive evidence that physical treatment, in particular insulin coma therapy, might have been effective in the subgroup of paranoid schizophrenic, but in the subgroups of hebephrenics and catatonic and atypical schizophrenics, a beneficial effect could not be conclusively demonstrated. The present communication deals with the same group of patients after they have been followed up for three years.

Appel, Myers, and Scheflen (1953) have summarized a large number of reports on the treatment of schizophrenia with insulin coma and electroconvulsion therapy. Most of these reports agree that after five years the results in treated and untreated cases are identical.

As regards the short-term prognosis, this appears better in the treated groups (particularly the insulin coma-treated group), but the methods used in evaluating the results have rarely been properly controlled.

The impression of Wilcox and Wilcox (1954) is that insulin coma therapy tends to be used less rather than more, in spite of the favourable results which continue to be reported from time to time. Kalinowsky (1954) is one of the few clinicians who still regard convulsive therapy as the method of choice in schizophrenia. It may be, therefore, that if the impressions of Wilcox and Wilcox are correct, either less physical therapy is being used for the treatment of schizophrenia or that Kalinowsky's view gains more followers and the place of insulin coma is being taken by E.C.T. (Bourne, 1953). While this is only speculation, based on rather scanty data, it would serve to indicate the need for more exact knowledge of the comparative effects of different physical treatments in this disease and of the results of physical treatments as a whole.

\section{Material and Methods}

The case material is in all respects the same as that reported in a previous communication published in this journal (Hoenig et al., 1956). Two groups are compared, a "test" group and a "control" group. The control group consists of the patients investigated and followed up by Guttmann, Mayer-Gross, and Slater (1939), and 
are all the schizophrenics discharged from the Maudsley Hospital between January 1, 1943, and December 31, 1955. These patients had prima facie a favourable outlook owing to the selective admission policy of the hospital. All patients were excluded who were over 46 years, whose illness had lasted more than 12 months before admission, or in whom there was the slightest doubt as to the diagnosis.

The test group consists of patients who were admitted for the first time as in-patients to the Bethlem Royal and the Maudsley Hospital between January 1, 1948, and December 31, 1950. It includes all patients suffering from schizophrenia between the ages of 16 and 46 years who had had no previous attacks and whose illness was of less than 12 months' duration. The treatment of this group falls into four main classes: Those who were given (1) insulin coma therapy, (2) electroconvulsive therapy, (3) a combination of the two, and finally (4) those who had no such treatment. Over the years following discharge from the Bethlem Royal and Maudsley Hospitals, a number of patients had further treatments, either E.C.T., insulin coma, or the two combined. The patients were admitted under the care of different clinicians on the staff of the Bethlem Royal and Maudsley Hospital, who made the diagnosis and selection for treatment.

As far as the diagnosis is concerned, this was scrutinized by the authors before any case was included in this group. Only a negligible number, however, had to be rejected, because of doubts about the accuracy of their diagnosis. The control and test groups are strictly comparable as far as the mean age, sex ratio, and duration of illness is concerned, but there is some difference between them in the relative proportions of the sub-groups of catatonic and atypical schizophrenia.

It has been shown previously (Hoenig et al., 1956) that there are good reasons for considering the groups of atypical and catatonic schizophrenics together since these subgroups overlap to a considerable extent. If this is done the proportions are comparable in the control and test groups. One hundred and thirty-seven patients in the control group are compared with 156 in the test group. The control group has $29.2 \%$ hebephrenic cases compared with $23.9 \%$ in the test group; $37.9 \%$ paranoid schizophrenic cases compared with $31.6 \%$ in the test group; and $32.9 \%$ combined catatonic and atypical cases compared with $44.5 \%$ in the test group.

The patients were followed up by a team of two psychiatrists and a psychiatric social worker. Wherever possible a clinical assessment at the time of the follow-up interview was made by one of the psychiatrists, and a relative or other informant was interviewed as well as the patient. In a proportion of cases the psychiatric social worker visited the patient at home. In many cases the patients were visited in other mental hospitals by a member of the team, and in these cases information was also gathered from the psychiatrist in charge or from the case records. Some patients could only be reached by letter, but in all such cases confirmatory evidence was sought from relatives, general practitioners, and others likely to have knowledge of the patient's condition. The sources of information were distributed in the following manner. Home visits by the social worker accounted for $10 \%$, interviews of the patients and their relatives for $29 \%$, information from hospitals, including visits to hospitals $33 \%$, and information by letter $27 \%$. Only two patients were untraced. Thus in 112 , or $72 \%$ of the 156 cases followed, expert testimony was available as to progress and present status. Of the remaining 44 , the majority, 25 or $16 \%$, were covered by confirmatory evidence supplied by relatives, friends, and general practitioners, and in only 17 cases or $11 \%$ had we to rely on the unsupported testimony of patients. In addition to the comparison of the control and test groups as a whole, the various diagnostic subgroups were compared separately.

As the test group is comprised of all schizophrenic patients admitted in the stated period, it is obvious that the test group also contains untreated patients, and this was used as an internal check, so to speak, by comparing the treated and untreated cases of the test group separately with the control group and also with each other.

\section{Classification of Results}

The classification of our results is the same as that used by Guttmann et al., 1939. The following categories, adopted from those suggested by Müller (1937), were used:-

Total recovery denotes freedom from symptoms and signs, return to the previous social environment and to the previous or to an equivalent occupation.

Social recovery means return to the previous social environment and to the previous or an equivalent occupation, in spite of minor signs and symptoms, such as irritability, shyness, shallowness of affective response, etc.

Social defect indicates minor symptoms as above, incapacity to carry out work of the previous level and the patient is unable to maintain himself in the same degree of social adaptation.

A family invalid is a patient with well-marked symptoms, unable to carry out any useful occupation, but manageable at home.

A hospital invalid is an inmate of a mental hospital, some of them continuously since discharge from the Bethlem Royal and the Maudsley Hospital, 
some relapsed after a temporary recovery.

This classification allows the test and control groups to be directly compared, and has several advantages for a follow-up assessment of psychiatric patients. It has, however, certain disadvantages when the short-term outcome is compared with the three year follow-up results, since it is impossible to make a direct comparison. The final classification in each case was the result of a collective assessment by the team.

\section{Results and Discussion}

Results of Test and Control Group Compared.-As Table I shows, the test group as a whole does much better than the control group. This trend is shown even more clearly when the classification of results is simplified into " improved " and " not improved ".

TABLE I

NUMBER AND PERCENTAGE OF PATIENTS IN EACH CATEGORY OF RESULTS FOR TEST AND CONTROL GROUPS

\begin{tabular}{|c|c|c|c|c|}
\hline \multirow{2}{*}{$\begin{array}{l}\text { Condition of } \\
\text { Patients } 3 \text { Years } \\
\text { after Admission }\end{array}$} & \multicolumn{2}{|c|}{ Control Group } & \multicolumn{2}{|c|}{ Test Group } \\
\hline & \multicolumn{2}{|c|}{ Number of Patients } & \multicolumn{2}{|c|}{ Number of Patients } \\
\hline $\begin{array}{l}\text { Total recovery } \\
\text { Social recovery } \\
\text { Social defect } \\
\text { Family invalids } \\
\text { Hospital invalids } \\
\text { Dead } \\
\text { Untraced }\end{array}$ & $\begin{array}{l}21(15.3 \%) \\
20(14.6 \%) \\
19(13.9 \%) \\
9(6.6 \%) \\
55(40.2 \%) \\
7(5.1 \%) \\
6(4.4 \%)\end{array}$ & $\left\{\begin{array}{c}\text { Improved } \\
60 \\
(43 \cdot 8 \%) \\
\text { Not } \\
\text { improved } \\
71 \\
(51.9 \%)\end{array}\right.$ & $\begin{array}{|cc|}49 & (31.4 \%) \\
36 & (23.1 \%) \\
13 & (8.3 \%) \\
10 & (6.4 \%) \\
44 & (28.2 \%) \\
2 & (1.3 \%) \\
2 & (1.3 \%)\end{array}$ & $\left\{\begin{array}{c}\text { Improved } \\
98 \\
(62.8 \%) \\
\text { Not } \\
\text { improved } \\
56 \\
(35.9 \%)\end{array}\right.$ \\
\hline Total & $137(100 \%)$ & & $156(100 \%)$ & \\
\hline
\end{tabular}

The improved group includes all patients who achieved total recovery, social recovery, or social defect. The " not improved " group comprises the hospital and family invalids and fatalities. (The number of untraced cases in both the test and control groups is so small that it cannot affect the overall results.) On the face of it, these results, which are statistically significant $(P<0.005)$, appear to support strongly the effectiveness of the physical treatments. If the test group is divided into the treated and untreated sections (Table Ia) we find that the treated section has 103 patients, of whom $71(68.9 \%)$ are improved as defined above, while the untreated section has 51 patients of whom $27(52.9 \%)$ fall into the improved category. Thus the untreated section does worse than the treated section, which would be expected if the treatments were effective but the significance is low (P 0.05). With $53 \%$ improved, the untreated section of the test group does somewhat better than the control group with $43.8 \%$ improved, but this difference is not significant $(\mathrm{P}>0 \cdot 1)$. These figures seem to temper the first impression that the treatment is highly effective. Although they do not show that the treatment is ineffective, they make its value appear somewhat doubtful. The untreated section
TABLE Ia

OVERALL RESULTS

\begin{tabular}{|c|c|c|c|}
\hline & \multicolumn{3}{|c|}{ All Cases } \\
\hline & \multirow[b]{2}{*}{ Control Group } & \multicolumn{2}{|c|}{ Test Group } \\
\hline & & $\begin{array}{l}\text { Treated } \\
\text { Section }\end{array}$ & $\begin{array}{l}\text { Untreated } \\
\text { Section }\end{array}$ \\
\hline Number of patients & $\begin{array}{c}131 \\
\text { (6 untraced) }\end{array}$ & 103 & $\frac{51}{(2 \text { untraced) }}$ \\
\hline $\begin{array}{l}\text { Improved } \\
\text { Not improved }\end{array}$ & $\begin{array}{l}43.8 \% \\
51.9 \%\end{array}$ & $\begin{array}{l}68.9 \% \\
31.1 \%\end{array}$ & $\begin{array}{l}52.9 \% \\
47.1 \%\end{array}$ \\
\hline
\end{tabular}

* "Improved " includes the categories total recovery, social recovery, social defect. "Not improved" includes family and hospital invalids and dead.

of the test group falls between the treated section and the control group. This is indeed what would be expected if the treatments were effective. The fact that the difference between the treated and untreated section is not very significant calls for further analysis.

It was shown in the previous communication (Hoenig et al., 1956) on the short-term prognosis of this group that the diagnostic subgroups differed considerably in outcome and a comparative analysis led to some modification of conclusions based on the preliminary analysis of the effects of treatment.

The test and control groups are now subdivided into their diagnostic subgroups, and each subgroup will be dealt with separately.

Hebephrenic Schizophrenia.-The results in this subgroup are shown in Table II. The close similarity between the figures in the various categories strongly suggests that in fact physical treatment has brought little or no benefit in this type of case. The control group has $50 \%$ improved compared with the test groups $49 \%$ improved. If the treated and untreated sections of the test group are compared, it will be seen that the treated section does better $(54 \%$ improved) and the untreated section correspondingly worse $(46 \%$ improved), a result probably due to chance selection of cases.

Paranoid Schizophrenia.-Table II shows that this subgroup behaves in a similar manner to the preceding one. The difference between the control and test groups is slightly in favour of the test group, $50 \%$ improved of the control being compared with $54 \%$ improved of the test group. This difference, however, is small and not significant. There is no sign of any difference between the treated and the untreated sections. It would be reasonable to conclude that treatment has made no significant contribution to the outcome here.

Catatonic and Atypical Schizophrenia.-Here the results in the test group are very much superior to those in the control group, $77 \%$ showing improvement (Table II) compared with $37 \%(\mathrm{P}<0.001)$. The treated section has an even better outcome with 
TABLE II

RESULTS IN CONTROL AND TEST GROUPS COMPARED

\begin{tabular}{|c|c|c|c|c|c|c|c|c|c|}
\hline & \multicolumn{3}{|c|}{ Hebephrenia } & \multicolumn{3}{|c|}{ Paranoid Schizophrenia } & \multicolumn{3}{|c|}{$\begin{array}{l}\text { Combined Catatonia } \\
\text { and } \\
\text { Atypical Schizophrenia }\end{array}$} \\
\hline & \multirow{2}{*}{$\begin{array}{l}\text { Control } \\
\text { Group }\end{array}$} & \multicolumn{2}{|c|}{ Test Group } & \multirow{2}{*}{$\begin{array}{c}\text { Control } \\
\text { Group }\end{array}$} & \multicolumn{2}{|c|}{ Test Group } & \multirow{2}{*}{$\begin{array}{c}\text { Control } \\
\text { Group }\end{array}$} & \multicolumn{2}{|c|}{ Test Group } \\
\hline & & Treated & Untreated & & Treated & Untreated & & Treated & Untreated \\
\hline $\begin{array}{l}\text { Number of patients } \\
\text { Improved }(\%) \\
\text { Not improved }(\%)\end{array}$ & $\begin{array}{c}38 \\
(2 \text { untraced) } \\
50 \\
50\end{array}$ & $\begin{array}{l}26 \\
54 \\
46\end{array}$ & $\begin{array}{l}11 \\
45 \\
55\end{array}$ & \begin{tabular}{|c|}
50 \\
$(2$ untraced) \\
50 \\
50
\end{tabular} & $\begin{array}{l}31 \\
55 \\
45\end{array}$ & $\begin{array}{c}17 \\
\text { (2 untraced) } \\
53 \\
47\end{array}$ & \begin{tabular}{|c|}
43 \\
(2untraced) \\
37 \\
63
\end{tabular} & $\begin{array}{l}46 \\
87 \\
13\end{array}$ & $\begin{array}{l}23 \\
57 \\
43\end{array}$ \\
\hline
\end{tabular}

$87 \%$ improved, while the untreated section with $57 \%$ improved shows an advantage over the control group, but not a significant one $(P>0 \cdot 1)$. We must conclude, therefore, either that the treatments given are highly effective in this particular subgroup, or else other factors are responsible. This point will be discussed later.

Effect of Subsequent Treatment on Outcome.-The analysis of results so far presented only refers to the treatment received on the first admission. Many of the patients received treatment subsequently in the course of the three years of follow-up. A detailed table is not presented since it was found that the effect on the group as a whole was not significant. A tendency within the test group became apparent for the patients with an unsatisfactory outcome to change over from the untreated section to the treated section, relatively worsening the results of the treated section and correspondingly improving those of the untreated section.

Evaluation of Effectiveness of Different Treatments.-Table III analyses the response of patients in the different diagnostic categories to various physical treatments and compares treated and untreated patients in the test group. The numbers in each category and each treatment group are small, but the general results are clear. There is no significant difference between treated and untreated patients in the paranoid and hebephrenic subgroups nor between the different types of treatment.

The catatonic and atypical subgroup shows a significant difference between the total treated and untreated sections $(P<0.01)$ and between the insulin coma-treated and the untreated sections $(P<0.02)$ but the differences between the E.C.T. section, the combined treatment section, and the untreated section are not significant. For example, the results of cases treated by E.C.T. versus untreated cases gave $P>0 \cdot 1$ and cases of combined treatment versus untreated cases gave $\mathbf{P}>0 \cdot 05$. Between the cases treated with insulin coma and those treated with E.C.T., the difference is not significant $(P>0.5)$, so that, while insulin coma is significantly effective compared with no treatment, it is not possible to evaluate the relative merits of the different treatments with respect to each other. The small numbers do not permit us to state definitely that there is a difference in effectiveness between insulin coma and E.C.T., though the evidence is suggestive.

Number of Comas. - It has been stated (MayerGross, Slater, and Roth, 1954; Kalinowsky and Hoch, 1952) that a minimum of 30 to 50 comas is required to produce the maximum therapeutic effect. We have therefore examined our group as to the number of comas in relation to outcome. If the patients are divided into those given more or less than $\mathbf{4 0}$ comas the outcome in the two groups does not seem very different.

The $40+$ group shows $68.8 \%$ improved, the -40 group $77.6 \%$. Furthermore, if the number of comas are compared according to outcome we do not find that the groups with better results had more comas. The figures are: Total recovery 33, social recovery 23 , social defect 39 , family invalids 42 , and hospital invalids 32 . If each treatment year is analysed separately it is found that although the

TABLE III

COMPARISON OF RESULTS OF DIFFERENT FORMS OF PHYSICAL TREATMENT AND NONE ON FIRST ADMISSION

\begin{tabular}{|c|c|c|c|c|c|c|}
\hline & & Insulin Coma & $\begin{array}{l}\text { Combined } \\
\text { Insulin Coma } \\
\text { and E.C.T. }\end{array}$ & E.C.T.* & No & Treatment \\
\hline Hebephrenia & $\begin{array}{l}\text { Improved } \\
\text { Not improved }\end{array}$ & $\begin{array}{l}8 \\
8\end{array}$ & $\begin{array}{l}4 \\
4\end{array}$ & 2 & & $\begin{array}{l}5 \\
6\end{array}$ \\
\hline Paranoid schizophrenia & $\begin{array}{l}\text { Improved } \\
\text { Not improved }\end{array}$ & $\begin{array}{l}12 \\
10\end{array}$ & $\begin{array}{l}3 \\
2\end{array}$ & $\begin{array}{l}2 \\
2\end{array}$ & & $\begin{array}{l}9 \\
8\end{array}>2$ untraced \\
\hline Catatonia and atypical schizophrenia & $\begin{array}{l}\text { Improved } \\
\text { Not improved }\end{array}$ & $\begin{array}{r}19 \\
2\end{array}$ & $\begin{array}{r}12 \\
2\end{array}$ & $\begin{array}{l}9 \\
2\end{array}$ & & $\begin{array}{l}132 \text { untraced } \\
10\end{array}$ \\
\hline
\end{tabular}

*Average $n \cdot$ mber of E.C.T. treatments was $8+2 \cdot 3$. 
outcome in each year does not alter much the number of comas does. In 1948 it was 37 comas $( \pm 12 \cdot 7)$, in 1949 it was 30.9 comas $( \pm 7 \cdot 6)$, and in 195033.6 comas $( \pm 7 \cdot 8)$.

We are aware that some authorities insist that the number of comas must be even more than 50 . Certainly this investigation cannot answer this question. The results described in this report are only valid if the treatment is carried out in the form described above. Since many insulin treatment units do in fact follow a similar policy we hope that our findings will have relevance to others.

Degree of Invalidism in the Two Groups.-It has been stated that insulin coma and electroconvulsive therapy, although not producing more " cures", still have a beneficial effect in enabling the patient to remain at work, or at least in keeping him out of hospital. Three years after admission to hospital the control group had spent an average of 1.5 years in hospital (S.D. $=12.2$ months). The figure for the test group is one year (S.D. $=11.7$ months). The difference is highly significant. If the test group is broken down into the treated and untreated sections we find that the two sections do equally well. The figures for the treated section are one year (S.D. 10.5 months) and for the untreated section also one year (S.D. 11.7 months). It cannot, therefore, be confirmed that treatment as such is responsible for the difference between the control and test groups. Other factors must have been operative in the years 1948-51 to cause patients to leave hospital earlier than they did in the years 1934-35.

Duration of Illness and Outcome.-We investigated whether the duration of the illness before the patient entered hospital had any effect on the outcome. Both the control and test groups show a better outcome the earlier the patient entered hospital. Forty-nine per cent of the control group ill for up to three months were improved after three years, $45 \%$ of those ill from four to six months, and $41 \%$ of those ill from seven to 12 months. In the test group $78 \%$ of those ill for up to three months were improved at the time of follow-up, $54 \%$ of those ill from four to six months, and $51 \%$ of those ill from seven to 12 months. A similar tendency is shown both in the treated and untreated sections. For example, of those ill up to three months, $85 \%$ of the treated and $61 \%$ of the untreated were improved, and $58 \%$ of the treated and $39 \%$ of the untreated in the group ill for seven to 12 months. The patients given one or other of the physical treatments seem to have some advantage at all stages of the illness up to 12 months. It is also noticeable that the untreated section of the test group does rather better than the control group, suggesting again that a nonspecific factor may partly be responsible.
Assessment of Results

From the foregoing analysis it seems that, although hebephrenic and paranoid schizophrenics do not show any improvement three years after admission to hospital when treated with physical methods, there appears to be a significant improvement in the results of the catatonic and atypical types of schizophrenia. As treatment is purely empirical, conclusions must be cautious, and it might well be that other factors could contribute to the superior results in these groups. It has been previously shown that several factors may affect prognosis, for example, age, sex, duration of illness, but in all these respects at least the two groups are similar. The possibility of a better prognosis for the test group as a whole has been commented on in the previous paper (Hoenig et al., 1956). The authors showed there that as far as perusal of the clinical reports could settle the matter, the type and severity of the illness in the two groups were very similar. If other factors were operative they are more difficult to assess; they could be constitutional influences or environmental influences, e.g., social background, home conditions, or family relationships, which this investigation has not taken into account.

Yet other influences of a more subtle charactern may be responsible for the differences in outcome of two groups which have passed through the hospital separated in time by 10 to 12 years. Such factors could include, e.g., growth of therapeutico optimism, or a more intensive general concern with the patient due to alterations in the ratios of doctors and nurses to patients which are known to have improved. In the Bethlem Royal and Maudsley Hospital the number of doctors has increased markedly since 1938, and so has the number of auxiliary workers such as psychiatric social workers, psychologists, occupational therapists, etc. This increase means that the individual patient has an environment which should make him feel (rightly or wrongly) that he is receiving more interest, and is the centre of more attention.

Another possible explanation of the observed differences between the test and control groups is that the illness has changed in the course of the years (Bourne, 1953). Other possible factors are suggested by the work of Crandell, Zubin, Mettler, and Logan (1954), who have observed that the "mobility" of the patient in and out of hospital, i.e., the number of leaves and "trials" correlate highly with prognosis, and it is likely that the Bethlem Royal and the Maudsley Hospital results also reflect this change towards increased mobility. It is a fact that the test group as a whole spent significantly less time in hospital than the control group.

However this may be, it is quite clear that possible 
changes in prognosis due to differences in the environment and in the composition of temporally separated groups of patients have to be taken into consideration when planning therapeutic trials. This is well known in relation to other illnesses (Reid, 1954). As far as schizophrenia is concerned, it has hitherto been too readily assumed that a group of patients, if it is similar in composition in all other respects, can serve as controls although it is separated in time from the group under test.

\section{Conclusion}

In comparing the short-term outcome of our two groups of schizophrenic patients, it was found that the test group which was admitted to hospital at a time when physical treatments were freely used did much better than the control group which was admitted 10 or 12 years earlier when these treatments were not in use. When the two groups were divided into diagnostic subgroups and then compared, using as an internal check the untreated part of the test group, it was only the paranoid schizophrenic subgroup which showed evidence of benefit from the physical methods of treatment employed (Hoenig et al., 1956). When the two groups were followed up over a period of three years they changed little relatively to each other, and the differences which existed between them when they left hospital were more or less maintained. Divided into diagnostic subgroups, the hebephrenic and paranoid schizophrenics show no apparent advantage from physical treatment after three years, that is, the paranoid schizophrenic group lost all the advantages it had at the time of leaving hospital. The physically treated section of the catatonic and atypical schizophrenics, however, shows an advantage over the untreated section and over the control group. If a comparison is made with the early outcome in this group as reported in the previous paper (Hoenig et al., 1956), it is seen that this group showed a high degree of improvement on leaving hospital. Since this short-term improvement is seen in both the treated and untreated sections of the test group, it could not be attributed to the treatments. The follow-up results seem to indicate that while the treated section is holding the initial improvement the untreated section has got worse. The fact that it is the catatonic and atypical schizophrenics who show the best spontaneous remission rates (Cheney and Drewry, 1938) might caution against too optimistic an assessment of the outcome in terms of the superiority of any particular method of treatment.

The evidence here is, unfortunately, no more than suggestive that physical treatment is effective in certain types of this unpleasant illness. Considering the many difficulties which beset this type of investigation, even a slightly positive finding must carry weight, and until some more rational and effective therapy is discovered, insulin coma and convulsion therapy must continue to be the basis of treatment.

As far as the type of treatment is concerned, the suggestion is that insulin coma is superior to E.C.T. (average number of treatments $=8$ ) though the superiority is not marked. Not surprisingly, combined treatment falls between the two, as it is mainly used in cases not responding well to insulin coma alone.

\section{Summary}

The clinical outcome, three years after admission, of a group of schizophrenic patients who entered the Bethlem Royal and Maudsley Hospital between 1948 and 1950, is compared with that in a similar group admitted to the Maudsley Hospital between 1934 and 1935.

The two groups are comparable in all relevant respects and consist entirely of patients whose illness is of less than 12 months' duration. A proportion of the patients in the 1948/1950 group received treatment by insulin coma, E.C.T., or combined therapy. The remainder had non-specific treatment.

The 1948/50 group (particularly the catatonic and atypical subgroup) did better than the 1934/35 group, and analysis suggests that this favourable result can possibly, but not certainly, be attributed to the special physical methods of treatment.

Other possible explanations for the different outcome in the two groups are discussed.

The necessity for a controlled therapeutic trial of physical treatments in schizophrenia is once again demonstrated.

We would like to thank Professor Aubrey J. Lewis for permission to carry out this investigation, and Dr. Eliot Slater for helpful criticism and advice. The protocols of the control group were made available to us through the kindness of Dr. W. Mayer-Gross and Dr. Eliot Slater.

\section{REFERENCES}

Appel, K. E., Myers, J. M., and Scheflen, A. E. (1953). A.M.A. Arch. Neurol. Psychiat., 70, 459.

Bourne, H. (1953). Lancet, 2, 964.

Cheney, C. O., and Drewry, P. H. (1938). Amer. J. Psychiat., 95, 203. Crandell, A., Zubin, J., Mettler, F. A., and Logan, N. D. (1954). Psychiat. Quart., 28, 185.

David, H. P. (1954). Amer. J. Psychiat., 110, 774.

Guttmann, E., Mayer-Gross, W., and Slater, E. T. O. (1939). J. Neurol. Psychiat., 2, 25.

Hoenig, J., Leiberman, D. M., and Auerbach, I. (1956). Journal of Neurology, Neurosurgery and Psychiatry, 19, 130.

Kalinowsky, L. B. (1954). Dis. nerv. Syst., 15, 377.

and Hoch, P. H. (1952). Shock Treatments, Psychosurgery and Other Somatic Treatments in Psychiatry, 2nd ed., p. 30. Grune and Stratton, New York.

Lewis, A. (1945). Brit. med. Bull., 3, 22.

Malamud, W., and Render, N. (1939). Amer. J. Psychiat., 95, 1039. Mayer-Gross, W., Slater, E., and Roth, M. (1954). Clinical Psychiatry, p. 286. Cassell, London.

Müller, M. (1937). Schweiz. Arch. Neurol. Psychiat., 39, Ergänzungsheft, p. 9 .

Reid, D. D. (1954). Lancet, 2, 1293.

Wilcox, P. H., and Wilcox, K. W. (1954). In Progress in Neurology and Psychiatry, Vol. 9, p. 584, Ed. Spiegel, E. A. Grune and Stratton, New York. 